\title{
O queijo e os vermes: o cosmo de um historiador do século $\mathrm{XX}^{*}$
}

\author{
Dominick LaCapra** \\ Cornell University
}

\begin{abstract}
...a a querer (a uma distância que é a do afastamento da dupla reflexáo) ler solo o texto original da existência-relação humana individual, o texto antigo, bem conhecido, transmitido pelos pais - lê-lo inteiramente uma outra vez, se possivel, de forma mais autêntica.
\end{abstract}

Søren Kierkegaard, Uma primeira e última declaração, Pós-escrito final não cientifico.

Então incentivaram-no a falar: Menocchio abandonou qualquer reticência.

Carlo Ginzburg, O queijo e os vermes

\section{RESUMO}

$O$ queijo e os vermes: o cosmo de um historiador do século $X X$ foi originalmente publicado em History \& Criticism, de 1985, coletânea de ensaios de Dominick LaCapra. Abertamente polêmico, realiza uma leitura cerrada de um texto clássico da historiografia do século XX, $O$ queijo e os vermes (1976), de Carlo Ginzburg, buscando, por aí, explicitar e problematizar certas tendências, então - e ainda -, predominantes na profissão histórica. O propósito de LaCapra é chamar a atenção dos historiadores para a necessidade de refletir sobre sua prática e desenvolver modos de interpretação mais críticos e autocríticos, num diálogo mais próximo com a crítica literária e a filosofia contemporânea. Ao traduzi-lo para o português, visamos contribuir para tornar a obra de LaCapra mais disseminada entre o público acadêmico brasileiro.

DOI - http://dx.doi.org/10.1590/2237-101X016030011

* The Cheese and the Worms: the Cosmos of a Twentieth-Century Historian. In: LACAPRA, Dominick. History \& Criticism. Ithaca e Londres: Cornell University Press, 1985. p. 45-69. Tradução de Renata Sammer e Joáo de Azevedo e Dias Duarte, respectivamente, mestre e doutor em História pelo Programa de Pós-Graduação em História Social da Cultura da Pontifícia Universidade Católica (PUC-Rio).

** Doutor pela Harvard University, LaCapra é titular da cátedra Bryce \& Edith M. Bowmar em Humanistic Studies no Departamento de História da Cornell University. 


\begin{abstract}
The Cheese and the Worms: the cosmos of a Twentieth-century historian was originally published in History \& Criticism (1985), a collection of essays by Dominick LaCapra. Openly polemic, the essay performs a close reading of a classic text of Twentieth-century historiography, The Cheese and the Worms (1976), by Carlo Ginzburg, seeking to make visible and problematize certain tendencies then - and still - prevalent in the historical profession. LaCapra's purpose is to call the attention of historians to the necessity of reflecting on their practice and developing modes of interpretation more critical and self-critical, in a closer dialogue with the disciplines of literary criticism and contemporary philosophy. In translating it into Portuguese, we seek to contribute to the wider dissemination of LaCapra's work among the Brazilian academic public.
\end{abstract}

Em 1983, passei os últimos dias de dezembro em Ithaca, Nova York. Teria preferido um lugar que oferecesse um clima mais temperado. Procurando abrigo do rigor inquisitorial de um inverno especialmente severo, encontrei meus pensamentos voltados, mais uma vez, para um tópico que tendia a preocupar-me no passado recente: o estado da historiografia contemporânea. O comentário meta-histórico pode ser algo de gelar os ossos. É um processo de dupla reflexão, duas vezes afastado do objeto ostensivo da investigação do historiador — um processo que faz a imediatez da experiência passada parecer especialmente remota. Como pode tal empreendimento, aparentemente desumano, capacitar alguém a ler velhos textos, de fato, o texto da própria existência, de forma mais autêntica? Eu preferiria dedicar meu tempo e minha energia a temas mais amigáveis, a assuntos de caráter narrativo — talvez, remexer os ricos depósitos de papéis arquivados e contar as suas fábulas em formas narrativas insinuantes. Entretanto, folheando as páginas de trabalhos históricos recentes, esbarro em alegaçóes que capturam a minha curiosidade e em configuraçóes de ideias que desafiam a minha compreensáo. Por vezes, eu quase pareço estar em outro mundo.

A historiografia hoje não está naquele estado de fermentação encontrado em campos tais como a crítica literária e a filosofia continental. Os historiadores tendem a orgulhar-se de sua imunidade diante da dúvida corrosiva e do escrutínio autorreflexivo que apareceram em outras áreas de investigação, especialmente naquelas infiltradas pelo pensamento francês recente. Longe de ver as iniciativas críticas recentes como emissárias da promessa angelical de uma reforma ou mesmo de um renascimento nos estudos históricos, muitos historiadores foram tomados pelo que se poderia quase chamar de um zelo contrarreformístico em reafirmar procedimentos ortodoxos. Mas a profissão histórica contemporânea não é um bloco sólido, e mesmo os acadêmicos mais tradicionais mostram-se abertos ao menos a alguns 
movimentos mais recentes. Se fôssemos generalizar de maneira um tanto ou quanto severa sobre as tendências proeminentes da profissão, listaríamos o seguinte: uma inclinação a apoiar-se em uma definição social de contexto como uma matriz explanatória; uma guinada em direção a um interesse pela cultura popular; uma reconceitualização da cultura em termos de discursos coletivos, mentalidades, visôes de mundo, e mesmo 'linguagens"; uma redefinição da história intelectual como o estudo dos significados sociais historicamente constituídos; e um realismo documental arquivístico, que trata os artefatos como jazidas de fatos na reconstituição das sociedades e culturas do passado. Essas tendências representam, de várias maneiras significativas, um progresso em comparação com práticas mais antigas, porém, podem se tornar ambíguas quando engendram sociocentrismo dogmático, populismo metodológico, a recusa em reconhecer a significância histórica de aspectos excepcionais da cultura e uma compreensão ultrassimplificada da linguagem e do significado, frequentemente acompanhada de um uso redutivo de textos e documentos.

Um livro recente que, penso, incorpora ambos, as promessas e os perigos das tendências contemporâneas, capturou a imaginação histórica: $O$ queijo e os vermes, de Carlo Ginzburg. ${ }^{1}$ É raro que um livro tão pequeno (128 páginas de texto principal, 15 de prefácio e 43 de notas) produza ondas tão grandes na profissão. Os tradutores de Ginzburg observam acuradamente: "o livro foi merecidamente louvado como uma das mais significativas contribuiçóes recentes a um campo de estudo florescente, a cultura popular na Europa moderna" (p. viii - edição em língua inglesa). Roger Chartier oferece uma explicação mais extensa sobre o porquê da atenção conferida ao livro:

Como nos mostra Carlo Ginzburg, quando os documentos autorizam, é inteiramente permitido explorar, como se por uma lente de aumento, a maneira como um homem do povo pode pensar e usar os elementos intelectuais esparsos da cultura literária que o alcançam por meio de seus livros e da leitura que ele faz deles. Aqui, Bakhtin é posto de ponta cabeça, uma vez que um sistema de representaçóes é construído a partir dos fragmentos emprestados da cultura acadêmica e livresca, aos quais outros significados são atribuídos, pois no fundamento do sistema há uma outra cultura: "por trás dos livros que Menocchio ruminava, identificamos um código de leitura e, por trás dele, um estrato sólido de cultura oral”. Não podemos, portanto, postular como necessária a conexão estabelecida por Felix Gilbert entre a ampliação social do campo de pesquisa em história intelectual e o recurso a procedimentos estatísticos. De fato, se, sob certas condições, a abordagem quantitativa (interna ou externa) aos textos mais elaborados pode ser aceita como legítima, por outro lado, quando os arquivos permitem, o trabalho intelectual do mais anônimo dos leitores pode ser submetido aos procedimentos analíticos comumente

\footnotetext{
${ }^{1}$ GINZBURG, Carlo. The Cheese and the Worms. Traduzido por John and Anne Tedeschi. Baltimore: Johns Hopkins University Press, 1980, primeiramente publicado em italiano, em 1976. Todas as referências são a essa edição. N.T.: Salvo indicado, utilizamos a edição brasileira para as citaçôes: O queijo e os vermes, tradução de Maria Betânia Amoroso. São Paulo: Companhia das Letras, 2006.
} 
reservados aos 'grandes' pensadores". 2

Assim, Ginzburg, por meio de uma variante imaginativa de pesquisa sobre a resposta de um leitor, revelou um modo de história social qualitativa que supostamente emprega técnicas da história intelectual "alta" ou de "elite". No processo, ele abre para nós o "cosmo" de um moleiro do século XVI, o inesquecível Domenico Scandella, chamado Menocchio. Apesar de não ser qualificado por especialização nem no campo nem no período, eu gostaria de arriscar ao menos uma leitura parcial do texto de Ginzburg — um texto que é suficientemente emblemático do "cosmo" do historiador do século XX. A semelhança entre O queijo e os vermes de Ginzburg vis-à-vis a profissão histórica contemporânea e a "visão de mundo" de Menocchio vis-à-vis a cultura popular do século XVI está, evidentemente, longe de ser completa. Ao passo que o notável livro de Ginzburg recebeu amplo reconhecimento, nem todos os historiadores que o elogiam concordariam com todos os aspectos de seu argumento, mesmo que possam assentir à sua concepção geral sobre a direção que a pesquisa histórica deve assumir. Ademais, para Ginzburg, temos um texto escrito, enquanto, para Menocchio, temos apenas uma "visão de mundo" putativa, reconstituída inferencialmente a partir de dois registros da Inquisição (há um intervalo de 15 anos entre os julgamentos, e Menocchio foi queimado na fogueira, quando velho).

Um motivo recorrente do livro de Ginzburg é a importância das discrepâncias entre o que ocorre nos textos que Menocchio lê e as leituras ativas, de fato agressivas, que Menocchio faz deles. Ginzburg interpreta essas discrepâncias sintomáticas como indicaçóes de uma cultura oral, popular (mais especificamente, camponesa), que inconscientemente serviu como o crivo ou filtro para as leituras de Menocchio. Gostaria de apontar uma discrepância entre o papel dessa interpretaçáo no argumento dominante do texto principal de Ginzburg e o que tende ocasionalmente a vir à tona em seus dois prefácios (um para a traduçáo em língua inglesa e o outro para a edição italiana), em uma importante nota de rodapé, e em breves comentários ao longo do texto que são expandidos em um crescendo vigoroso, quase explosivo, à medida que chegamos ao fim do texto principal. Essa discrepância indica uma tensão importante na concepção de Ginzburg sobre o que Menocchio representa e, de maneira mais geral, em sua exposiçáo das relaçóes entre as culturas popular, alta e dominante no século XVI e ao longo do tempo. Pode-se inicialmente formular essa tensão em termos do contraste entre uma ideia de autonomia da cultura popular e uma ideia de sua interação recíproca ou circular com a cultura dominante ou hegemônica. Veremos como essa formulação inicial é inadequada, entretanto, ela atesta a força do compromisso de Ginzburg com uma concepção de cultura popular que, se não autônoma, é primordial ou basilar no "cosmo" de Menocchio.

\footnotetext{
${ }^{2}$ CHARTIER, Roger. Intellectual History or Sociocultural History? The French Trajectories. In: LACAPRA, Dominick; KAPLAN, Steven L. (Orgs.). Modern European Intellectual History: Reappraisals and New Perspectives. Ithaca: Cornell University Press, 1982. p. 35-36.
} 
Comecemos com o argumento que parece ser dominante no texto principal, ao menos até suas páginas conclusivas. Ele apresenta a cultura oral, popular e camponesa, como um fenômeno muito antigo, fundamentalmente pré-cristão, que a agitação da Reforma permitiu que emergisse, rompendo a crosta das formas culturais mais visíveis. Ginzburg partilha essa visão com Mikhail Bakhtin, e sua inovação é apresentá-la como um "código" oral, que modela a leitura de Menocchio de textos escritos. Eis uma das típicas formulaçôes de Ginzburg dessa visão:

Qual a relação entre uma cosmogonia como a de Menocchio - o queijo primordial do qual nascem vermes que são os anjos - e a Reforma? Como remeter à Reforma afirmaçôes como as atribuídas a Menocchio por seus conterrâneos: "Tudo o que se vê é Deus e nós somos deuses"; "O céu, a terra, o mar, o ar, o abismo e o inferno, tudo é Deus"? É melhor imputá-las, por enquanto, a um substrato de crenças camponesas, velho de muitos séculos, mas nunca totalmente extinto. A Reforma, rompendo a crosta da unidade religiosa, tinha feito vir à tona, de forma indireta, tal substrato; a Contrarreforma, na tentativa de recompor a unidade, trouxera-o à luz, para expulsá-lo. Seguindo essa hipótese, as afirmaçóes de tom radical feitas por Menocchio não serão explicadas se remetidas ao anabatismo, ou, pior ainda, a um genérico "luteranismo". Antes, devemos nos perguntar se elas não fazem parte de um ramo autônomo de radicalismo camponês que o tumulto da Reforma contribuíra para que emergisse, mas que era muito mais antigo do que a Reforma. (p. 56)

Ao longo do livro, a atribuição da "visão de mundo" de Menocchio a uma cultura popular oral ou a um radicalismo camponês (aqui explicitamente denominado "autônomo") se torna muito mais que uma "hipótese", tanto no sentido científico quanto no ordinário. Cientificamente, a interpretação de Ginzburg (como ele reconhecerá na nota de rodapé que ainda vamos discutir) não pode ser provada de acordo com os critérios mais comuns de verificação e falsificação. Eu, contudo, aceitaria a condição da "visão" como uma "hipótese" no sentido mais ordinário. É bastante plausível argumentar que as ideias de Menocchio têm uma relaçáo significativa com tradiçóes orais e populares de idade indeterminada. Contudo, a natureza da relação entre essas tradiçóes orais e outros aspectos ou níveis de cultura ainda seria controversa. Igualmente controverso seria o seu papel em comparação a outros fatores e forças na leitura de Menocchio de textos escritos e sua interação com outros aspectos da cultura.

Parte da atraçáo da concepção de Bakhtin de uma cultura popular oral imemorial reside no fato de que - apesar de sua evocação periódica de uma metafísica fonocêntrica - ele a mantém numa condição relativamente "hipotética" (no sentido ordinário), não a rotiniza nem coloca uma carga "científica" excessiva sobre ela, e a usa retoricamente para motivar in- 
terpretaçóes amiúde perspicazes. ${ }^{3}$ Ginzburg, contudo, exige mais da concepção que adapta de Bakhtin, buscando resolver questôes controversas em uma direção particular. Para ele, uma cultura oral, popular e camponesa, vista como autônoma ou, ao menos, como primordial e basilar, é a chave para as leituras e para a "visão de mundo" de Menocchio. Todas as metáforas que Ginzburg emprega assumem a condição basilar da cultura oral no "cosmo" de Menocchio. Encontramos metáforas arqueológicas e arbóreas, às vezes combinadas de modo a indicar a condiçấo incontestavelmente privilegiada da cultura popular oral, por exemplo, em uma frase tal como "num veio profundo de radicalismo camponês trazido à luz pela Reforma" (p. 72). E, em uma nota, nos é dito que Ginzburg escolheu o termo "radicalismo camponês" de acordo com a "frase de Marx, que diz que o radicalismo 'toma as coisas pela raiz' - uma imagem que, além de tudo, se adapta de maneira perfeita ao contexto” (p. 216, nota). Encontramos também metáforas oculares: "mais do que o texto, portanto, parece-nos importante a chave de sua leitura, a rede que Menocchio de maneira inconsciente interpunha entre ele e a página impressa - um filtro que fazia enfatizar certas passagens enquanto ocultava outras, que exagerava o significado de uma palavra, isolando-a do contexto, que agia sobre a memória de Menocchio deformando a sua leitura. Essa rede, essa chave de leitura, remete continuamente a uma cultura diversa da registrada na página impressa: uma cultura oral” (p. 72).

As obsessivas metáforas de Ginzburg conduzem-nos, como seus leitores, aos seus investimentos significativos na ideia de uma cultura primordial, oral e popular - investimentos metafísicos, literários e metodológicos.

Metafisicamente, Ginzburg elabora a oposição binária entre fala e escrita em termos reminiscentes de Claude Lévi-Strauss, em um capítulo intitulado "Lição de escrita", em Tristes trópicos. ${ }^{4}$ Desse modo, ele cede a um fonocentrismo que faz da escrita um bode expiatório e reprime, na própria fala, as características projetadas exclusivamente sobre a escrita. Nas palavras de Ginzburg:

Desse modo, [Menocchio] viveu pessoalmente o salto histórico de peso incalculável que separa a linguagem gesticulada, murmurada, gritada, da cultura oral, da linguagem da cultura escrita, desprovida de entonação e cristalizada nas páginas dos livros. Uma é como um prolongamento do corpo; a outra é 'coisa da mente'. A vitória da cultura escrita sobre a oral foi, acima de tudo, a vitória da abstraçấo sobre o empirismo. Na possibilidade de emancipar-se das situaçóes particulares está a raiz do eixo que sempre ligou de modo inextricável escritura e

\footnotetext{
${ }^{3}$ Sobre Bakhtin, ver LACAPRA, Dominick. Bakhtin, Marxism, and the Carnivalesque. In: Rethinking Intellectual History: Texts, Contexts, Language. Ithaca: Cornell University Press, 1983. p. 291-324.

* N.T. A referida combinação de metáforas arqueológicas e arbóreas, ausente na tradução brasileira, foi mantida na norte-americana: "a deeply rooted current of peasant radicalism brought to the surface by the Reformation". ${ }^{4}$ LÉVI-STRAUSS, Claude. Tristes Tropiques. Nova York: Penguin 1974 [1955], cap. 28, p. 294-304. Há tradução brasileira: Tristes trópicos. São Paulo: Companhia das Letras, 1996.
} 
poder... Compreendia que a escritura e a capacidade de dominar e transmitir a cultura escrita eram fontes de poder... (p. 104-105)

Assim, a autoridade da suposta experiência de Menocchio é evocada para autenticar a palavra falada e relegar a escrita à esfera suspeita do poder — o recurso da cultura hegemônica ou dominante. Os estratagemas gerais envolvidos em uma metafísica fonocêntrica, e sua relação com um mito das origens perdidas, foram tão amplamente "desconstruídos" por Jacques Derrida que é supérfluo repetir aqui este gesto 5 (Ginzburg menciona Derrida no prefácio à edição italiana, mas é apenas para descartar como "superficiais" e "niilistas" suas críticas à História da loucura de Foucault - críticas que Ginzburg parece ter entendido mal). Basta notar que a palavra falada não é desprovida de poder, como a performance oral dos próprios inquisidores seria suficiente para mostrar. Tampouco é a escrita invariavelmente uma "coisa da mente" abstrata — de fato, ela nunca é simplesmente uma "coisa da mente". O problema é o das diferenças empíricas variáveis entre fala e escrita (bem como entre sociedades "pré-literatas" e sociedades nas quais a fala é suplementada pela escrita) — um problema cuja articulação, com referência a circunstâncias e contextos específicos, a metafísica evocada por Ginzburg prontamente funciona de modo a obscurecer. Para o historiador, o interesse da extensão da noção de écriture de Derrida, de modo a abarcar tanto a fala quanto a escrita (no sentido ordinário), é o de problematizar oposiçôes universais tendenciosas entre as duas e deslocar o ônus da prova, em casos específicos, para a pesquisa concreta. Talvez não seja irrelevante observar que a "experiência" de Menocchio, tal como descrita pelo próprio Ginzburg, não se presta a uma metafísica fonocêntrica. Menocchio tinha um respeito profundo pelos livros, lia-os com intensidade e paixão, e buscava autorização para suas visóes no que lia. "Lera poucos livros, em geral por acaso. Desses, mastigara, triturara cada palavra. Ele os ruminava durante anos; durante anos palavras e frases fermentaram em sua cabeça” (p. 87). A maneira como Menocchio lia poderia por si mesma indicar que sua escolha de livros não era tão fortuita como Ginzburg acredita. Ele tinha, por exemplo, consideração especial por um livro que se adequa mal à tese da primordialidade da cultura oral e camponesa: a Bíblia, "um livro diferente dos demais porque continha um núcleo dado por Deus" (p. 70). Como veremos, contudo, o ponto não é apenas inverter a ênfase de Ginzburg e chegar à imagem de um Menocchio piedosamente livresco; mas antes questionar a persuasividade das inversóes simples em geral, sejam a favor da cultura popular, camponesa e oral, sejam a favor da alta cultura, escrita e hegemônica (uma oposição excessivamente simples, postulada, ademais, em séries de termos que não são de todo coincidentes).

A própria ideia de Ginzburg sobre a importância primordial da cultura oral na leitura e

\footnotetext{
${ }^{5}$ Ver especialmente DERRIDA, Jacques. Of Grammatology, trans. Gayatri Chakravorty Spivak. Baltimore: Johns Hopkins University Press, 1976 [1967], pt. 2, cap. I. p. 101-140. Há tradução brasileira: Gramatologia. São Paulo: Perspectiva, 1973.
} 
no "cosmo" de Menocchio é reforçada por uma metodologia estruturalista e pela confiança em uma forma literária particular: a história de detetive. Sua narrativa é estranhamente anedótica e geométrica, projetivamente empática e redutivamente analítica, extremamente fragmentada (62 capítulos para 128 páginas, alguns capítulos contendo apenas um ou dois parágrafos) e demasiadamente unificada em tema e tese. O objeto de sua busca é obviamente uma estrutura profunda, e a sua noção de um código, filtro ou crivo privilegiado provê um dispositivo reducionista conveniente para dar um sentido total e unificado aos comentários registrados de Menocchio. Uma metodologia estruturalista um tanto ou quanto rígida poderia ser, ela própria, vista como a "estrutura profunda" de uma narrativa "superficialmente" difusa e por vezes descosida. Em um outro nível, o próprio formato da história de detetive garante que a pergunta "quem-é-o-assassino" revelará um único agente: a cultura popular oral. De fato, a convergência fatal das suposiçóes metafísicas, metodológicas e narrativas, em uma ideia fundamental de cultura oral cria no leitor a sensação de que há uma relação cega de transferência entre Ginzburg como intérprete e Menocchio como Ginzburg o "lê" Menocchio que supostamente lia de forma "parcial e arbitrária - quase uma mera procura de confirmação para ideias e convicçôes já estabelecidas de maneira sólida” (p. 76).

Deve-se notar, antes de dar continuidade à indagação sobre a natureza da cultura popular oral no relato de Ginzburg, que uma metodologia estruturalista tem um efeito paradoxal. Ginzburg quer, com razão, opor-se ao preconceito de que todas as ideias emanam originalmente da alta cultura ou das classes dominantes — que elas vêm das "cabeças dos monges e dos professores universitários, e certamente náo de moleiros e camponeses" (p. 155, nota - edição em língua inglesa) (talvez, esse preconceito deva ser menos contraposto — já que a contraposiçâo engendra apenas o inverso - , do que simplesmente descartado como patentemente ridículo). Ele quer mostrar a natureza ativa das leituras de Menocchio. Não obstante, a ênfase sobre a cultura oral como um código privilegiado que Menocchio inconscientemente emprega retorna o moleiro à passividade em um outro plano, e reduz a mera superficialidade a sua determinaçáo e audácia. Na medida em que Menocchio é uma figura da cultura popular, tal ênfase obscurece o fato de que pode haver exceçóes no plano da própria cultura popular. Ademais, essa ênfase depende de um conceito estrutural (ou fixação) do inconsciente como um crivo ou filtro que unifica a experiência. Desse modo, ela reprime a "noção" mais desafiadora e desestabilizadora do inconsciente como um nome paradoxal para processos de repressão, deslocamento e condensação — processos que trazem à tona a importância do problema da própria relaçáo de transferência do historiador com o passado, bem como da necessidade de elaborar essa relação de maneira crítica e autocrítica. Náo obstante, é essa inevitável relação de transferência que revela, em termos mais específicos, como Menocchio está "muito perto de nós: é um homem como nós, é um de nós" e como sua história "coloca implicitamente uma série de indagaçóes para nossa própria cultura e para nós” (prefácio à edição em língua inglesa, p. 9-10). 
Qual é a natureza da cultura oral, popular e camponesa, que eu repetidamente evoquei, mas deixei um tanto ou quanto envolta em mistério? É preciso confessar que sua natureza é também algo misteriosa em $O$ queijo e os vermes. A narrativa difusa e o estilo anedótico facilitam o seu tratamento em termos vagos, fragmentados e alusivos. Ela é com maior frequência evocada do que descrita ou analisada, e sua clareza está em relação inversa a seu suposto poder explicativo. Esse fato afina-se, talvez, com a dimensão metafísica do relato de Ginzburg, no qual a "cultura popular" adquire traços usualmente associados a um "termo-Deus". De nada ajuda quando, próximo ao fim do livro, Ginzburg apela ao Settennario de Scolio como encarnação da elusiva tradição oral, pois, embora o poema tenha sido escrito por um "rústico desconhecido", inclui elementos de fé fundamentalista nos Dez Mandamentos, iconoclastia, desejo por um estilo simples, elogio da sobriedade e da piedade, uma concepçáo frugal da vida apropriada, uma ideia extramundana de utopia, intolerância dogmática, anti-intelectualismo, e um ânimo anticarnavalesco (p. 171-177). O fato de que o poema foi escrito por um "rústico desconhecido" levanta questôes a respeito da unidade da cultura popular oral, mesmo quando essa última é restringida ao campesinato, pois essa cultura não era tão homogênea em suas tradiçôes e práticas como as referências de Ginzburg a ela sugerem. Ela abrigava diferenças e divisóes internas, bem como internalizava aspectos da cultura dominante, notadamente da Cristandade. Evidentemente, Ginzburg não ignora esse ponto, mas isso tem muito pouca importância na estória que ele conta. Uma variante crucial desse ponto, contudo, emerge com referência à figura do próprio Menocchio, especialmente à luz de algumas consideraçóes proeminentes nas páginas conclusivas de Ginzburg.

Quatro características da cultura popular oral parecem sobressair como particularmente relevantes nos comentários dispersos pelo relato de Ginzburg. Primeiro, há um materialismo expresso, por exemplo, na cosmogonia do queijo e dos vermes de Menocchio e em seu questionamento das doutrinas de um deus criador, da divindade de Cristo, da imaculada concepção e da imortalidade das almas. Aqui, contudo, nota-se que Menocchio, ao contrário de Ginzburg, náo se empenha na busca por um nível primordial ou fundacional de explicação, seja dando prioridade à cultura oral sobre a cultura escrita, seja estipulando algum princípio ou entidade singular como a causa primeira das demais. Em suas variaçôes da história de como o mundo era como um queijo de onde os anjos e o próprio Deus emergiram, Menocchio é bastante flexível, até maleável, ao discutir as relaçóes entre o caos, Deus, e "a santíssima majestade". Em certo ponto ele argumenta que "tudo era um caos [...] e de todo aquele volume em movimento se formou uma massa, do mesmo modo como o queijo é feito do leite, e do qual surgem os vermes, e esses foram os anjos. A santíssima majestade quis que aquilo fosse Deus e os outros, anjos" (citado na p. 97). Aqui, o caos parece ser primário, e "a santíssima majestade", diferenciada de Deus, parece ter o papel de um demiurgo legislador. Em resposta à questão do vigário-geral sobre a natureza dessa santíssima majestade, Menocchio diz que ele a concebe como "o espírito 
de Deus, que sempre existiu” (p. 98). Aqui, o espírito de Deus é coevo do caos e precede Deus. Em outra versão, contudo, Menocchio torna Deus eterno e troca as posiçóes entre Ele e o Espírito Santo. Em resposta à questão do inquisidor, Menocchio, segundo relatado, responde: "eu acredito que sempre tenham estado juntos, nunca separados, isto é, nem o caos sem Deus, nem Deus sem o caos" (p. 98). Diante de questionamentos inquisitoriais ulteriores, Menocchio diz ser Deus eterno com o caos, mas que inicialmente a sua união é apenas implícita - "[Deus] não conhecia a si próprio e nem era vivo, mas depois se conheceu, e isso é o que eu entendo por ter sido feito do caos" (p. 98). Mais adiante em seu próprio relato, Ginzburg oferece uma redução linear enganosa das visôes transmitidas de Menocchio: “o caos precede a 'santíssima majestade', que não é melhor definida; do caos nasceram os primeiros seres viventes - os anjos e mesmo Deus, que era o maior de todos — por geração espontânea, 'produzidos pela natureza'” (p. 102). Poder-se-ia, por contraste, insistir que há valor nas formulaçóes mais flexíveis de Menocchio, especialmente com referência ao nosso próprio análogo secularizado delas: a busca por explicaçôes unificadas ou por níveis primordiais em relação às forças que contestam essa mesma busca. Os próprios gestos explanatórios de Ginzburg neste quesito aproximam-se, às vezes, da lógica inquisitorial que ele explicitamente rejeita.

Um segundo elemento da cultura camponesa é um igualitarismo combinado a uma visão da sociedade existente como dividida entre "superiores" e "homens pobres" (p. 50). Menocchio via a hierarquia eclesiástica como uma encarnação essencial da opressão, porquanto a Igreja era ainda uma grande proprietária de terras. "A essa construção colossal baseada na exploração dos pobres, Menocchio contrapõe uma religiâo bem diferente, em que todos são iguais, porque o espírito de Deus está em todos” (p. 52).

Um terceiro elemento é a tolerância, em um sentido positivo, relacionada com o reconhecimento "da equivalência de todas as fés, em nome de uma religião simplificada, sem caracterizaçôes dogmáticas ou confessionais” (p. 94). Nas palavras transmitidas de Menocchio: "A majestade de Deus distribuiu o Espírito Santo para todos: cristáos, heréticos, turcos, judeus, tem a mesma consideração por todos, e de algum modo todos se salvarão" (p. 94). Ou ainda: "eu penso que cada um acha que a sua fé seja a melhor, mas não se sabe qual é a melhor" (citado com ênfase acrescentada, p. 94).

Em quarto lugar, há um utopismo mundano. "A imagem de uma sociedade mais justa era projetada de maneira consciente num futuro não escatológico. Não o Filho do Homem no alto, sobre as nuvens, mas homens como Menocchio - os camponeses de Montereale que ele tentara inutilmente convencer, por exemplo - através de sua luta, deveriam ser os mensageiros do 'mundo novo'” (p. 139). É curioso que, a despeito de se apoiar em Bakhtin e de reconhecer que "no centro da cultura configurada por Bakhtin está o carnaval" (prefácio à ediçấo italiana, p. 15), Ginzburg não pondere sobre o papel efetivo do carnaval em Montereale, nem sobre o significado do fato de que uma das ocupaçóes do próprio Menocchio 
— como tocador de violáo nos festejos - poderia ser vista como carnavalesca. Tampouco Ginzburg enfatiza a relação entre carnaval e utopia. Em Bakhtin, o carnaval é a utopia mundana, realista, que se alterna de maneiras variáveis com práticas sérias, rotineiras, e que caracteriza um modo de vida no qual é legítimo ter tanto relaçóes "sérias" quanto "jocosas" com as mesmas crenças ou instituições. Com efeito, para Bakhtin, tudo torna-se melhor quando se pode brincar com aquilo que se tem por mais sagrado.

Uma questão inevitável é se "algumas investigaçôes confirmam a existência de traços que reconduzem a uma cultura camponesa comum”, como Ginzburg afirma (prefácio à edição italiana, p. 21). Em que medida os quatro traços notáveis que eu extraí do relato de Ginzburg são exclusivos à cultura camponesa, originalmente desenvolvidos na cultura camponesa (na qual parece, às vezes, haver um iluminismo popular avant la lettre), ou especialmente prevalecentes na cultura camponesa? Ginzburg não oferece respostas a essas questôes, nem mesmo as formula de forma suficientemente clara e distinta. Ele gostaria de afirmar a existência de uma tradição oral imemorial, que seria o repositório privilegiado dos traços que ele vê e admira em Menocchio. Não obstante, Ginzburg oferece evidências de que, no século XVI, os camponeses e citadinos que Menocchio "tentara inutilmente convencer" também abrigavam outras tendências, e mesmo contracorrentes. Não apenas o testemunho deles nos julgamentos de Menocchio parece indicar a assimilação de aspectos da cultura dominante, como também parece haver tendências no campesinato que não podem ser concebidas somente como derivativos miméticos ou internalizaçôes da cultura dominante, por exemplo: um grau de intolerância em relação a forasteiros. Inversamente, pode-se argumentar que os traços atribuídos à cultura popular oral possuíam certos análogos no cristianismo, como por exemplo: a crença "materialista" na ressurreição do corpo, o igualitarismo das correntes evangélicas, e a propensão das visôes extramundanas de uma utopia celestial para converter-se em protesto mundano. Mais significativo, talvez, é o fato de que o cristianismo pré-Reforma fora relativamente tolerante em relaçáo a heterodoxias, tolerante em demasia para os reformadores, que desejavam uma espiritualidade mais rigorosa e que devem ter achado difícil distinguir entre tolerância e abuso. Em certo sentido, Menocchio parece ser, entre outras coisas, característico da pré-Reforma em seu próprio entendimento expansivo do cristianismo.

Essas observaçóes levantam o que é a maior e mais premente questão: quais eram as relações variáveis, ao longo do tempo - incluindo a relação entre ortodoxia e heterodoxias na interaçáo entre cultura(s) hegemônica(s) das classes dominantes, cultura(s) popular(es), e alta(s) cultura(s)? Ginzburg não explora essa questão de uma maneira suficientemente discriminante. Com efeito, ele é impedido de fazê-lo por sua insistência no papel de uma cultura popular unificada como a chave para o "cosmo" de Menocchio e por sua confiança na oposição binária entre cultura dominante e cultura popular. Em seu prefácio retrospectivo, escrito para a edição em língua inglesa, Ginzburg refuta a acusação de que teria atribuído "autono- 
mia absoluta” à cultura popular e, recorrendo a Bakhtin, afirma, ao contrário, a existência de uma "circularidade": "entre a cultura das classes dominantes e a das classes subalternas existiu, na Europa pré-industrial, um relacionamento circular feito de influências recíprocas, que se movia de baixo para cima, bem como de cima para baixo (exatamente o oposto, portanto, do 'conceito de absoluta autonomia e continuidade da cultura camponesa' que me foi atribuído" (p. 10). No prefácio à edição italiana original, há um comentário similar que também se ampara numa referência a Bakhtin: "temos, por um lado, dicotomia cultural, mas, por outro, circularidade, influxo recíproco entre cultura subalterna e cultura hegemônica, particularmente intenso na primeira metade do século XVI” (p. 15). Entretanto, vimos que Ginzburg, no corpo do texto principal, refere-se, sim, a "um ramo autônomo de radicalismo camponês" (p. 56), além de investir consideravelmente na ideia de um substrato primordial de crenças camponesas. Perto do final do texto principal, Ginzburg verte suas visóes numa perspectiva histórica de mais longo prazo:

Rabelais e Bruegel não foram, provavelmente, exceçóes notáveis. Todavia, fecharam uma época caracterizada pela presença de fecundas trocas subterrâneas, em ambas as direçóes, entre a alta cultura e a cultura popular. O período subsequente, ao contrário, foi assinalado tanto por uma distinção cada vez mais rígida entre cultura das classes dominantes e cultura artesanal e camponesa como pela doutrinação das massas populares, vinda de cima. Podemos localizar o corte cronológico entre esses dois períodos na segunda metade do século XVI, que coincide significativamente com a intensificação das diferenças sociais sob a influência da revolução dos preços. Mas a crise decisiva ocorrera algumas décadas antes, com a guerra dos camponeses e o reino anabatista de Münster. Então se impôs às classes dominantes, de maneira dramática, a necessidade de recuperar, mesmo ideologicamente, as massas populares que ameaçavam escapar a qualquer forma de controle vindo de cima - porém mantendo e até acentuando as distâncias sociais. (p. 189-190)

Essa passagem enfatiza a reciprocidade ou circularidade dos intercâmbios no início do século XVI, e percebe uma "quebra" na segunda metade do século. No entanto, ela muda os termos de comparação da relação entre "a alta cultura e a cultura popular", no período inicial, para aquela entre a "cultura das classes dominantes e [a] cultura artesanal e camponesa", no período subsequente, como se "alta" e "dominante" fossem termos equivalentes, e como se camponeses e artesãos pudessem ser amalgamados, ao menos no período posterior. Os termos e as comparaçôes do argumento geral parecem confusos e contraditórios: uma tradição autônoma, ou ao menos basilar, de cultura camponesa está, não obstante, em relação recíproca ou circular com uma alta cultura (ou, às vezes, cultura dominante) no início do século XVI, embora uma quebra sobrevenha na segunda metade do século. Ora, como é possível que uma cultura camponesa seja ao mesmo tempo autônoma (ou ao menos primordial, fundamental, infraestrutural - a chave, o filtro, o crivo, e assim por diante) e esteja envolvida em relaçóes 
recíprocas ou circulares com uma cultura dominante? Mesmo correndo o risco de se enovelar em monótonos exercícios semânticos ou, ainda pior, de reproduzir sobre o texto de Ginzburg uma variante da lógica inquisitorial, esperar-se-ia maiores esclarecimentos.

A nota de rodapé nas páginas 154-155 [ediçâo em língua inglesa] — - outra adição retrospectiva ao texto - ao mesmo tempo acrescenta uma luz e intensifica a confusão. Mais uma vez, Ginzburg nega a acusação de "autonomia absoluta" e reafirma as relaçóes circulares ou recíprocas, sem buscar explicar a relação entre autonomia (apenas simples?) — ou, ao menos, primordialidade - e reciprocidade (admitindo, talvez, uma autonomia "relativa" paradoxal). Entretanto, Ginzburg faz esta surpreendente concessão: "é legítimo objetar que a hipótese que reconduz as ideias de Menocchio sobre o cosmo a uma remota tradição oral também não está comprovada - estando, talvez, destinada a manter-se assim... ainda que, como afirmei anteriormente, pretenda, no futuro, demonstrar a sua possibilidade com evidências adicionais"; acrescentando, em seguida, este comentário espantoso: "de qualquer modo, seria recomendável desenvolver novos critérios de prova especificamente adaptados a uma linha de pesquisa baseada numa documentação tão perfeitamente heterogênea e instável. Que um novo campo de investigação altere não apenas os métodos mas também os próprios critérios de prova numa dada disciplina é demonstrado, por exemplo, na história da física: a aceitação da teoria atômica necessitou uma mudança nos padrôes de evidência que haviam sido desenvolvidos na esfera da física clássica" (p. 155 - edição em língua inglesa). Retornarei em breve à questão da documentação. A referência a critérios alterados de prova é, contudo, surpreendente, e a referência à física parece não mais do que diversionismo. No texto de $O$ queijo e os vermes, é, em grande medida, a força de um desejo metafísico por uma estrutura profunda, primordial, na história e nos esforços de explicação do historiador, que impele os movimentos contraditórios no argumento, e as únicas alteraçóes nos critérios de prova parecem ocorrer na direção de uma mitologia secular que, especialmente em suas formas não reconhecidas, pode ter implicaçōes profissionais duvidosas. Uma referência ao encontro de Freud com o "crime primordial" ou à admissão de Lévi-Strauss de que, no limite, ele também oferece um mito — o mito da mitologia — teria sido mais apropriada.

A nota de rodapé de Ginzburg torna explícita uma consideração que, embora periodicamente adumbrada, não é adequadamente explorada no corpo do texto principal: a hegemonia e sua relevância para a reciprocidade nas relaçôes. Tal como Ginzburg observa: "a cultura dominante e a cultura subalterna competem em uma luta desigual, na qual os dados estão viciados" (p. 155, nota - edição em língua inglesa). Um efeito da ênfase de Ginzburg na cultura popular oral, bem como de sua técnica narrativa no texto principal, é que a cultura hegemônica ou dominante permanece como uma categoria em grande medida residual, e mesmo como uma imagem do radicalmente "outro". É bastante claro que o inquisidor pode

\footnotetext{
* N.T.: A passagem referida, presente na edição em língua inglesa, não existe na edição brasileira. Portanto, as traduções relativas a ela são de nossa responsabilidade.
} 
condenar Menocchio à fogueira por heresia, ao passo que Menocchio não pode punir o inquisidor por dogmatismo intolerante e ortodoxia rígida. Entretanto, aprendemos pouco sobre aqueles que perseguem Menocchio ou sobre as relaçóes entre autoridades religiosas e seculares numa estrutura hegemônica. Aqui, a empatia de Ginzburg pelos oprimidos induz a uma percepção evanescente, fragmentária, dos opressores, cujos próprios problemas, ansiedades e motivaçôes permanecem recobertos por um véu de silêncio.

Em relação à questáo da cultura hegemônica, é possível introduzir o problema da documentaçáo em um sentido um pouco diferente daquele de Ginzburg. Um registro da Inquisição é, como observa Ginzburg, parte dos “arquivos da repressão”. Pesaroso, Ginzburg comenta no prefácio à edição italiana que o grosso da evidência que temos sobre a cultura popular vem desses repositórios da cultura hegemônica, e que a reconstrução de crenças e práticas populares deve ser inferencial e indireta. Porém, suas reflexôes parecem terminar nesse ponto, e sua única preocupação parece ser a de encontrar novos caminhos para fazer inferências sobre a "realidade", a qual está tentado a conceber em termos metafísicos e mitológicos. No texto principal, o enredo e o formato analítico já estão bem assentados antes que haja indicaçôes de que Ginzburg os está baseando em registros da Inquisição, e o fato de que ele o faz nunca se torna problemático. Ademais, a despeito de sua insistência na oposição, concebida em termos de uma metafísica questionável, entre o oral e o escrito, Ginzburg não trata da dificuldade colocada pelo problema mais específico do registro escrito do testemunho oral por escrivães da Inquisição. Tampouco reconhece a importância do que se poderia ironicamente chamar de la question préalable - a necessidade de uma leitura crítica, rigorosa, de documentos tais como os registros da inquisição, antes que sejam usados como jazidas de fatos ou fontes para reconstruções inferenciais da "realidade". Pois esses documentos são em si mesmos realidades históricas, que não apenas representam mas também suplementam as realidades às quais se referem, e uma leitura crítica deles pode fornecer percepçôes sobre os processos culturais - percepçôes de um tipo que, no mínimo, resiste aos desejos mitologizantes. Um registro da Inquisição é, em primeiro lugar, parte de um contexto discursivo que incorpora relaçôes hegemônicas, e um estudo rigoroso da natureza das perguntas e repostas pode proporcionar um entendimento concreto da ação mútua entre dominação e "reciprocidade" assimétrica. Ao menos o leitor merece uma transcrição do próprio registro da Inquisição para estar em uma posição melhor para testar o uso e a interpretação dele feitos. Quando uma fonte tal como essa é usada simplesmente como uma jazida ou como um ponto de referência ocasional para uma história ou para uma reduçáo analítica, ela é efetivamente silenciada e o leitor fica desamparado em sua tentativa de estabelecer uma apreciaçáo crítica do relato do historiador. Essa dificuldade é especialmente pronunciada em $O$ queijo e os vermes, no qual é amiúde impossível tratar criticamente da questão a respeito do que está vindo de Menocchio e do que está sendo projetado por Ginzburg. Em qualquer interpretação, há momentos em que é impossível responder a esse tipo 
de questão, mas é preciso ter alguma base para levantá-la e para estimar quando ela se torna irretorquível, especialmente quando o componente interpretativo do relato é acentuado e a relação de transferência entre o historiador e o seu tema é particularmente intensa. É ao tornar públicos os textos que se interpreta e ao proporcionar uma leitura rigorosa - crítica e autocrítica - deles que a história social pode extrair algo de valoroso de procedimentos que são (ou deveriam ser) importantes na história intelectual. Levantar esses pontos não é eliminar a tarefa de empregar documentos na reconstruçáo inferencial de outros eventos e processos; é, contudo, adicionar outra camada de investigaçáo àquela tarefa — uma camada que pode torná-la mais responsável cognitivamente.

Juntei alguns comentários dispersos em $O$ queijo e os vermes para formar uma configuração de ideias algo diferente daquela predominante no argumento de Ginzburg. Minha ênfase recairia na interação complexa, com frequência distorcida, entre níveis ou aspectos da cultura e na relação concomitante entre ortodoxia e heterodoxia na vida intelectual e social. A cultura popular oral, da qual a cultura camponesa é um componente, pode ser reconstituída apenas de uma forma bastante incerta, dada a natureza da evidência. E, como indica Ginzburg, as forças de resistência à cultura hegemônica encontram-se amiúde entre os silêncios do passado, os quais devem ser considerados pelo historiador. Todavia, esse esforço não implica que a "voz" do historiador domine completamente o passado. Tampouco exclui a necessidade de investigar os modos de acomodação às forças dominantes, pois esses oferecem um contexto realista para a apreciação da natureza - mais ou menos excepcional ou disseminada - da própria resistência. Com efeito, o historiador deve estar alerta para a possibilidade de tensôes e contradiçôes no interior de uma cultura tanto quanto entre os seus níveis, incluindo a cultura popular. Ginzburg critica a história das mentalidades por sua "insistência nos elementos inertes, obscuros, inconscientes de uma determinada visão de mundo" e por sua "conotação terminantemente interclassista" (p. 23-24). Entretanto, ele não apenas ameaça reproduzir em um outro nível a insistência no inconsciente estrutural, como também tende a deslocar a suposiçáo de uniformidade cultural da sociedade como um todo para as relaçôes dentro de uma classe ou de um nível de cultura.

A própria cultura hegemônica não é um todo homogêneo; ela varia ao longo do tempo, e as suas fissuras ou incertezas, em qualquer momento dado, oferecem espaços nos quais a resistência pode se manifestar. Em certos períodos, pode ser até difícil discernir o que é hegemônico ou ortodoxo. Por meio do conflito, a Reforma e a Contrarreforma intensificaram a unidade no interior dos grupos antagônicos, e é possível que tenha havido "uma distinção cada vez mais rígida entre cultura das classes dominantes e cultura artesanal e camponesa" (p. 190). Contudo, o século XVI em geral foi um período em que a própria hegemonia estava em questáo, e as linhas de comunicação não estavam completamente partidas, notadamente (como assinala Ginzburg) entre segmentos da cultura popular e da alta cultura. A Igreja pré-Reforma podia se dar ao luxo de ser relativamente tolerante, na medida em que os 
desafios a ela não se haviam cristalizado em movimentos organizados em grande escala e em instituiçóes alternativas. Quando do aparecimento da Reforma, a crosta náo estava simplesmente partida de maneira a permitir a emergência de heterodoxias. Tal como nos primeiros séculos do cristianismo, a própria natureza da ortodoxia tinha de ser definida (ou redefinida), e a extensão dos desafios, tanto da parte de protestantes de várias confissóes quanto da parte de heterodoxias relativamente não cristấs (bem como de diversas misturas), ajudou a gerar ansiedade e intolerância dogmática. A própria Igreja Católica exibiu alguns dos traços espiritualmente mais "rigorosos" dos seus críticos reformados — incluindo a sua "seriedade" e ímpeto anticarnavalesco - , não apenas para combatê-los de maneira mais efetiva como também devido aos elementos internamente persuasivos das formas mais recentes. Há uma troca importante entre Menocchio e o inquisidor a esse respeito. Em resposta a uma das recorrentes questóes relativas às suas discussôes com outrem sobre os artigos de fé, Menocchio diz que falara "sobre artigos da santa fé com alguns, por brincadeira". O inquisidor replica: “como 'brincar' com as coisas da fé? É justo brincar com coisas da fé?” (p. 161). De uma perspectiva diferente, e de certa forma mais antiga, o que é lamentável é que essas questóes poderiam ser reduzidas ao nível tolo da indignação retórica. Não obstante, como indica Ginzburg, os próprios inquisidores podiam, em certos momentos, estar inseguros a respeito de crenças ou procedimentos, e essa incerteza permitia ao menos um pequeno espaço para as iniciativas de Menocchio.

Se houve relaçóes mais verdadeiramente recíprocas entre os níveis da cultura, as quais parecem ter permanecido ao longo do século XVI, essas tiveram lugar entre segmentos da cultura popular e da alta cultura. Nesse ponto, ademais, cultura hegemônica e alta cultura não podem ser simplesmente equiparadas. Em um sentido óbvio, cultura dominante, ou hegemônica, pode ser vista como uma forma de alta cultura, e aspectos da alta cultura (no sentido de obras de uma elite cultural) podem reforçar a cultura hegemônica. Entretanto, a própria alta cultura pode abrigar forças de resistência e crítica que são mais efetivas socialmente quando se conectam com aspectos da cultura popular. Se Frances Yates estiver certa, tendências heterodoxas eram às vezes prevalecentes, talvez até "dominantes", nas elites culturais ao longo do século XVI. ${ }^{6}$ Como o próprio Ginzburg repetidamente nota, havia no mínimo convergências entre as visóes de Menocchio e aquelas avançadas nos círculos mais "progressistas" da alta cultura, particularmente entre humanistas "heréticos".

Nesse ponto, podemos retornar à complexa figura de Menocchio e às questóes relativas ao que essa figura pode nos dizer a respeito da interaçáo entre níveis ou aspectos da cultura em seu tempo e ao longo do tempo. Em seu prefácio à edição italiana, Ginzburg assevera que "mesmo um caso-limite (e Menocchio com certeza o é) pode se revelar representativo"

\footnotetext{
${ }^{6}$ Conferir YATES, Frances. Giordano Bruno and the Hermetic Tradition. Chicago: University of Chicago Press, 1964. Há tradução brasileira: Giordano Bruno e a tradição hermética.São Paulo: Cultrix, 1964 e The Occult Philosophy in the Elizabethan Age. Londres: Routledge, 1979.
} 
(p. 21). Mas em que sentido exatamente seria ele o portador representativo ou exemplar da cultura camponesa, popular e oral? Em certo sentido - mas quão preciso se é possível ser a esse respeito? - Menocchio é "representativo". Contudo, ele é também algo além de representativo. Ele é excepcional, não "um camponês 'típico”" (p. 20) — nem mesmo (se me permitem um trocadilho atroz) um moleiro meão. Menocchio parece ser excepcional na maneira como articula crenças comuns, excepcional em sua resistência a pressóes, tanto em sua comunidade vilareja quanto nos julgamentos inquisitoriais. Ele é talvez excepcional até em sua própria variante de desejo metafísico, em seu "impulso irrefreável de 'procurar as coisas grandes" — um impulso que o "atormentava” (p. 168). Mesmo quando se tornou um velho isolado, acometido de amarga ironia, ele não estava inteiramente quebrado. Também isso parece deveras excepcional.

Contudo, mesmo num sentido mais obviamente sociocultural, há algo de excepcional (“individual” poderia ser uma palavra melhor) em Menocchio, e sua condição — em larga medida reprimida ao longo do texto de Ginzburg — parece emergir com força nas páginas finais. Eu sugeriria que Menocchio era "representativo" e "excepcional”, no sentido peculiar de ser uma figura liminar — uma posição que o afeiçoava ao papel de bode expiatório diante da Inquisição. Sua posição era liminar entre a cultura popular e a cultura de elite, bem como entre a cultura oral e a cultura escrita. A ideia de que a cultura oral é o crivo principal de Menocchio parece particularmente suspeita em vista do modo como Menocchio estava dividido entre o "mundo" da cultura oral e aquele dos livros que tanto significavam para ele. Com efeito, o caso do outro moleiro (Pighino) que foi julgado pela Inquisição — um caso citado por Ginzburg em grande medida para sublinhar a "representatividade" de Menocchio - também serve para enfatizar sua liminaridade. Embora, em certos aspectos, uma figura menos impressionante do que Menocchio, Pighino pode, de fato, ter participado das leituras do famoso herético Paolo Ricci, mais conhecido como Camillo Renato (e que também atendia pelo nome humanista de Lisia Fileno) (p. 184 e 185). Aqui, haveria um contexto discursivo efetivo conectando elementos da cultura popular com segmentos heterodoxos da alta cultura. Ainda mais surpreendente: Ginzburg nota que o julgamento de Menocchio em 1599 quase coincidiu com aquele de Giordano Bruno — uma quase coincidência "que poderia simbolizar a dupla batalha, para cima e para baixo, conduzida pela hierarquia católica naqueles anos" (p. 191).

Ademais, em certos aspectos, Menocchio estava também situado no limiar entre a cultura popular e a cultura dominante. Ele queria intensamente estabelecer um intercâmbio com os seus "superiores" e, às vezes, esse desejo alimentava sua impudência. Nas palavras de Ginzburg, Menocchio "sentira a necessidade de se apropriar ainda do patrimônio de conhecimentos de seus adversários, os inquisidores. Percebe-se, portanto, no caso de Menocchio, um espírito livre e agressivo, decidido a acertar contas com a cultura das classes dominantes" (p. 179). Essa necessidade — eu acrescentaria — parece muito moderna, pois é uma neces- 
sidade que confronta os críticos, hoje, em todos os níveis da cultura.

Porém, a complexidade dessa figura da resistência não termina aqui. Menocchio era, de fato, alguém que teve muitos papéis sociais no nível da própria cultura popular, incluindo, de forma proeminente, aqueles de camponês e moleiro. Ele lavrava a terra e, não obstante, vestia-se com o traje branco tradicional do moleiro. Perto do fim do livro, Ginzburg introduz consideraçóes que indicam tanto a existência de certas tensóes nas classes populares quanto a posição especial dos moleiros na cultura popular:

A hostilidade secular entre camponeses e moleiros consolidara a imagem do moleiro esperto, ladrão, enganador, por definição destinado às penas do inferno... A acusação de heresia casava muito bem com tal estereótipo. Contribuía para alimentá-la o fato de o moinho ser um lugar de encontros, de relaçóes sociais, num mundo predominantemente fechado e estático. Um lugar de troca de ideias, como a taverna e a loja... As próprias condições de trabalho faziam dos moleiros - analogamente aos taverneiros, comerciantes, artesãos ambulantes - um grupo profissional aberto às ideias novas e propenso a difundi-las. Além disso, os moinhos, situados em geral longe das habitaçóes e dos olhares indiscretos, serviam muito bem de abrigo para reuniões clandestinas. (p. 181-182)

Temos, então, Menocchio — moleiro, camponês e tocador de violão nos festejos — resistindo à cultura hegemônica, não obstante querendo entrar em controvérsia com ela, profundamente interessado em certos livros, e transmitindo uma cultura oral conectada a certos aspectos heterodoxos da alta cultura. Poder-se-ia também chamá-lo de protointelectual, uma versão primitiva do que Gramsci viria a chamar de intelectual "orgânico”, um intelectual vindo das classes populares, não obstante capaz de abordar a cultura hegemônica e a alta cultura no interesse dos oprimidos? Talvez. Ginzburg indica como Menocchio confrontou um problema que se havia tornado familiar no período moderno: aquele de se dirigir a uma audiência dividida. "Ele apresentava aos concidadãos ignorantes uma versão simplificada, exotérica, de suas ideias: 'Se pudesse falar, falaria, mas não quero falar'. A versão mais complexa, esotérica, era, entretanto, reservada para as autoridades religiosas e seculares, a elas desejava com ardor se dirigir: 'Eu disse', declarou aos juízes de Portogruaro, 'que, se me fosse permitida a graça de falar diante do papa, de um rei ou príncipe que me ouvisse, diria muitas coisas, e, se depois me matassem, não me incomodaria” (p. 112-3).

Qualquer que tenha sido o caso na época de Menocchio, períodos posteriores manifestariam formas exacerbadas desse problema, e os intelectuais puderam se esquivar da necessidade de falar em duas vozes, à medida que a própria cultura popular parecia sitiada, senão apagada, e novos modos de dominância tomavam forma. Mesmo a apropriação na alta cultura de tradiçõos populares mais antigas poderia assumir formas esotéricas ou herméticas, que as faziam inacessíveis a uma audiência mais ampla. E, como destaca Ginzburg numa nota de 
rodapé, o período moderno acrescentou uma outra dimensão da cultura, a cultura mercantilizada ou de massa - algo que ainda não existia no século XVI, ao menos em nenhuma forma que se aproximasse da sua forma moderna (p. 200, n. 3). A cultura mercantilizada afeta todos os outros níveis da cultura e tem relaçóes complexas com a cultura hegemônica em geral e com a cultura estatal oficial em particular. A extensão em que ela assimilou a própria cultura popular, bem como a extensão em que é pontuada por forças de crítica e resistência, é uma história intrincada, cuja exposição nos levaria muito longe.

Todavia, a proximidade de Menocchio, "um homem como nós, [...] um de nós", um homem cuja história "coloca implicitamente uma série de indagaçóes para nossa própria cultura e para nós" (p. 9), é uma questão multifacetada. O que eu enfatizaria, na conclusão, é a relevância da dimensão de transferência da pesquisa na própria profissão histórica. $\mathrm{Na}$ academia, temos testemunhado, em pequena escala, a emergência de várias heterodoxias, e nos encontramos em um ponto em que a própria definição de ortodoxia está em questão. Como sempre, há uma relaçâo significativa entre questôes intelectuais e questôes institucionais. Ver Menocchio predominantemente como portador de uma cultura popular oral, à qual é conferida uma posição privilegiada na interpretação, facilmente serve para reforçar as relaçôes hegemônicas na historiografia profissional. Se um certo nível da cultura representa a realidade primordial, então, é um passo muito curto para a suposição de que aqueles que a estudam são os "verdadeiros" historiadores, aqueles que se concentram nas coisas mais importantes. Poder-se-ia facilmente reunir evidência oral e escrita para apoiar o argumento de que um certo número de historiadores deu esse passo. O resultado é um paradoxo bizarro e vicioso, no qual uma relaçấo vicária com os oprimidos do passado serve como pretexto para pretensôes contemporâneas de dominação. Porém, um entendimento diferente dos problemas pode promover um relato mais acurado da interação entre aspectos da cultura no passado, bem como uma concepção construtiva das suas relaçôes desejáveis no presente, tanto dentro da profissão histórica quanto além dela ${ }^{7}$

\footnotetext{
${ }^{7}$ Os elogios a $O$ queijo e os vermes têm sido muitos. Porém, a recepção do livro entre os especialistas não esteve destituída de reação crítica. Para a sua mais extensa análise crítica, que, de uma forma restrita, converge com o argumento deste ensaio, ver ZAMBELLI, Paola. Uno, due, tre, mille Menocchio? Archivo storico italiano, 137, p. 51-90, 1979. Essa é a crítica à qual Ginzburg tenta responder na longa nota de rodapé à edição em língua inglesa (p. 154-155), que eu discuti. Ver também as reservas contidas nas resenhas de COHN, Samuel Jr. Journal of Interdisciplinary History, 12, p. 523-25, 1982; MIDELFORT, Erik H. C. Catholic Historical Review, 68, p. 513-14, 1982; VALERI, Valerio. Journal of Modern History, 54, p. 139-143, 1982. Embora tenha aparecido antes da publicação de $O$ queijo e os vermes, "Carlo Ginzburg", de SCHUTTE, Anne Jacobson. Journal of Modern History, 48, p. 296-315, 1976, contém algumas observaçôes que são pertinentes ao seu argumento. Schutte enfatiza o papel da óbvia animosidade de Ginzburg em relação à Igreja Católica e em favor da cultura "pagã”. Eu escolhi enfatizar a relevância um tanto ou quanto menos aparente da abordagem de Ginzburg para a própria profissão histórica. Schutte também levanta algumas questôes penetrantes sobre as limitaçôes no uso de Ginzburg dos registros da Inquisição como fontes.
} 


\section{Referências bibliográficas}

CHARTIER, Roger. Intellectual History or Sociocultural History? The French Trajectories. In: LACAPRA, Dominick; KAPLAN, Steven L. (Orgs.). Modern European Intellectual History: Reappraisals and New Perspectives. Ithaca: Cornell University Press, 1982.

COHN, Samuel Jr. Book Review. Journal of Interdisciplinary History, 12, p. 523-25, 1982. DERRIDA, Jacques. Gramatologia. Sáo Paulo: Perspectiva, 1973. . Of Grammatology, trans. Gayatri Chakravorty Spivak. Baltimore: Johns Hopkins University Press, 1976 [1967].

GINZBURG, Carlo. O queijo e os vermes. São Paulo: Companhia das Letras, 2006. . The Cheese and the Worms. Baltimore: Johns Hopkins University Press, 1980.

LACAPRA, Dominick. Bakhtin, Marxism, and the Carnivalesque. In: Rethinking Intellectual History: Texts, Contexts, Language. Ithaca: Cornell University Press, 1983. . History \& Criticism. Ithaca e Londres: Cornell University Press, 1985.

LÉVI-STRAUSS, Claude. Tristes trópicos. São Paulo: Companhia das Letras, 1996. . Tristes Tropiques. Nova York: Penguin, 1974 [1955].

MIDELFORT, Erik H. C. Book Review. Catholic Historical Review, 68, p. 513-14, 1982.

SCHUTTE, Anne Jacobson. Book Review. Journal of Modern History, 48, p. 296-315, 1976.

VALERI, Valerio. Book Review. Journal of Modern History, 54 p. 139-143, 1982.

YATES, Frances. Giordano Bruno and the Hermetic Tradition. Chicago: University Of Chicago Press, 1964. . Giordano Bruno e a tradição hermética. São Paulo: Cultrix, 1964.

YATES, Frances. The Occult Philosophy in the Elizabethan Age. Londres: Routledge, 1979. ZAMBELLI, Paola. Uno, due, tre, mille Menocchio? Archivo storico italiano, 137, p. 51-90, 1979. 